\title{
Relacionándonos en un mundo diverso: un problema social contemporáneo*
}

\author{
Clara Victoria Meza Maya**
}

Recibido: 7 de febrero de 2012 Evaluado: 10 de marzo de 2012 Aceptado: 12 de abril de 2012

\section{RESUMEN}

El presente artículo tiene como finalidad abordar cómo se establecen relaciones culturales en un mundo diverso, en el marco del siguiente problema: ¿cómo caracterizar la persistencia de unas prácticas sociales que invocan y rememoran a aquellas que se han instaurado desde la Colonia? Y a partir de allí determinar cómo se establecen las relaciones culturales en un mundo diverso, vistos estos modos de relación como un problema social contemporáneo. En su discusión, se exploran tres propuestas: el multiculturalismo, como la coexistencia, en un mismo espacio, de grupos que reclaman tanto reconocimiento de su identidad como el derecho a la diferencia, y establece fronteras claramente definidas y promueve la convivencia bajo los preceptos de la tolerancia; la interculturalidad, que propende a una convivencia fortalecida por la integración de las culturas, cimentada en el mutuo respeto por la diversidad, y se asume como la probabilidad de una interacción fecunda entre sujetos diversos, lograda especialmente a través del diálogo; finalmente, el diálogo ch'ixi y su proyecto mestizo, como una apuesta y una postura política que opta por un lenguaje comprometido que persigue y genera consecuencias en la práctica social.

Palabras clave: diálogo $c h^{\prime} i x i$, historia oral, interculturalidad, lengua, multiculturalismo, proyecto mestizo, relaciones culturales.

* Artículo de investigación. Muestra los resultados de un proyecto de investigación para obtener el título de magíster en Investigación en Problemas Sociales Contemporáneos de la Universidad Central.

** Comunicadora social y periodista. Magíster en Investigación en Problemas Sociales Contemporáneos. Especialista en Comunicación-Educación. Docente en las áreas de Teorías de Comunicación y Lenguaje, en la Facultad de Comunicación Social para la Paz de la Universidad Santo Tomás, Bogotá. Investigadora en los campos de la memoria y la tradición oral. Correo electrónico: claravictoriamaya@yahoo.es 


\title{
Interacting in a diverse world: a contemporary social problem
}

\begin{abstract}
The purpose of this article is to address how cultural relationships are established in a diverse world, in the framework of the following problem: how to characterize the persistence of social practices that invoke and remember those that have been established since Colonial times? And from there, determine how cultural relations are established in a diverse world, seen these types of relations as a contemporary social problem. In the discussion, three aspects are explored: multiculturalism, as the coexistence in one same space of different groups that claim recognition of their identity as well as right for a difference, and establishes clearly defines boundaries and promotes coexistence under precepts of tolerance: interculturalism which tends towards strengthened coexistence by the integration of cultures, founded on mutual respect for diversity, and is assumed as a the probability of a fruitful interaction between diverse subjects, achieved especially through dialogue; finally, the ch'ixi dialogue and its mestizo project, as a political and social stance that opts for a committed language that pursues and generates consequences in the social practice.
\end{abstract}

Keywords: Ch'ixi dialogue, oral history, interculturality, language, multiculturalism, mestizo project, cultural relations. 


\section{INTRODUCCIÓN}

La cultura es un corpus de mutabilidad constante, de difusas delimitaciones, de pluralidad, de alteridades y de enunciación. Las relaciones de encuentros/desencuentros culturales nos sitúan rápidamente ante conceptos como "aculturación", "transculturalidad", "culturas híbridas", "traducción cultural", "multiculturalidad" o "interculturalidad". Asimismo, estas relaciones aluden a tipos de complejas relaciones que se establecen a través de los contactos y que impregnan, modifican o transforman las culturas.

En las sociedades actuales, los "encuentros" culturales suponen el reconocimiento de los rasgos diferenciales que constituyen a cada uno de los grupos participantes; sin embargo, esas relaciones se sitúan frente a la presuposición de las diferencias y, sobre todo, de las desigualdades. Cuando las diferencias se convierten en desigualdades, las relaciones entre culturas pueden establecerse como debates por espacios de poder en los territorios compartidos. De ahí, entonces, que existan unas culturas elevadas a posiciones de dominio que han naturalizado la dominación y que la consideran su destino.

Con estas premisas, abordamos el siguiente problema: ¿cómo caracterizar la persistencia de unas prácticas sociales que invocan $\mathrm{y}$ rememoran a aquellas que se han instaurado desde la Colonia? Y a partir de allí, ¿cómo se establecen las relaciones culturales en un mundo diverso, vistos estos modos de relación como un problema social contemporáneo?

Para su abordaje presentamos tres modos de entender y de definir dichas relaciones: el multiculturalismo, con su apuesta por el intercambio cultural basado en la tolerancia de lo ajeno y preservación de lo propio, en un mundo cada vez más globalizado; la interculturalidad, que se fundamenta en el diálogo y que propende al reconocimiento del otro y a la integración de las diferencias; finalmente, el diálogo ch'ixi y su proyecto mestizo, como una apuesta política que exige el reconocimiento y el establecimiento de lenguajes y temporalidades no impuestas y perpetuadas desde la Colonia.

\section{LOS ENCUENTROS DE LOS MUNDOS: UN PROBLEMA SOCIAL CONTEMPORÁNEO}

Geertz (1997) describe la cultura como una urdimbre: tramas de significación en las que el hombre está inserto y que él mismo ha tejido; cultura que durante los últimos tiempos, como lo propone Jameson (1998), ha sufrido profundas transformaciones, las cuales, a su vez, significan una honda mutación de su función social, hasta el punto en que todo lo que se encarna en el ámbito social se ha vuelto cultural.

El siguiente poema de Maya $\mathrm{Cu} \mathrm{Choc}^{1}$ nos sitúa en el vórtice de los encuentros culturales: mestizajes, rupturas, distanciamientos:

1 Maya Cu Choc es una de las más reconocidas poetas guatemaltecas contemporáneas. Nació en Ciudad de Guatemala, en 1968. Entre sus obras están Recorrido (2005), Poemaya (2002) y La rueda (1997). Este poema se encuentra en dos versiones complementarias en: La Rueda - Maya Cu: http://www. literaturaguatemalteca.org/ mayacu2.htm, y en: Elvir, Ley: Cuando la primera persona habla en femenino. Cuerpo e identidad en la poesía contemporánea escrita por mujeres. Universidad Nacional Autónoma de Honduras: http:// letrasuruguay.espaciolatino.com/aaa/elvir_lety/cuando_la_primera_persona.htm 
Vivo

desanclada de una mitad de alma.

Anduve esquivando el reojo

y mi espíritu creció temeroso

de mundos ajenos.

Mi casa

fue cueva que escondía

milenios que de a poco

fueron sorbidos en mi tarde.

Me fui tostando junto a mi madre

y me hice doblemente mujer

cargada de vergüenza,

de culpa,

de lenguas.

En mí

navega una doble identidad: soy

invariablemente

una hija más de este suelo y de su

historia.

Soy india sin idioma y sin vestido,

soy ladina sin piel,

sin refinamiento.

Son identidades cargadas de culpas y de vergüenzas en razón del sexo, de la raza, de la historia. Es la validación de unas culturas frente a otras, ante las cuales pueden ser consideradas deficientes para el desenvolvimiento social y que deben ser perfeccionadas en el acogimiento de modelos ofrecidos por culturas que, mayoritarias o no, se conciben a sí mismas como hegemónicas.

El abordaje de la cultura y de sus entramadas relaciones implica pensar en una multiplicidad de formas de ser, de saber y de entender, de sentir y de soñar, de relacionarse y de vivir. En el mundo actual, toda cultura es el resultado de interacciones, de mezclas que se fecundan en una abundancia de contingencias, que pueden producir nueva vida, hermosa o monstruosa, fecunda o yerma.

En el proyecto oficial de la Organización de las Naciones Unidas para la Educación, la Ciencia y la Cultura (Unesco) se plantea que dado que la cultura se observa como una forma de convivir en la que se entretejen relaciones sociales, en estas sociedades cada vez más diversificadas resulta indispensable "garantizar una interacción armoniosa y una voluntad de convivir de personas y grupos con identidades culturales a un tiempo plurales, variadas y dinámicas", bajo unas políticas que favorezcan la integración y la participación colectiva de los ciudadanos y promuevan "la cohesión social, la vitalidad de la sociedad civil y la paz"; en últimas, unas políticas que definan al pluralismo cultural como "la respuesta política al hecho de la diversidad cultural". Este pluralismo, inseparable de un contexto democrático, "es propicio para los intercambios culturales y el desarrollo de las capacidades creadoras que alimentan la vida pública" (Unesco, 2001).

$\mathrm{Y}$ en esos marcos las preguntas proliferan: ¿cómo nos relacionamos en un mundo cuyas diversidades confluyen cada vez de manera más frecuente?, ¿cómo nos relacionamos en unas sociedades en las que, a menudo, las diferencias justifican la discriminación?, ¿cómo se asumen las relaciones cuando las diferencias son subvaloradas, escasamente toleradas y difícilmente valoradas por unos grupos que se entienden y se asumen intrínsecamente superiores a los otros?, ¿cómo se establecen las relaciones en sociedades en las que las diferencias son pasivamente aceptadas?, ¿cómo se establecen las relaciones cuando quienes comparten un mismo territorio evidencian palpables diferencias?, ¿cómo y bajo qué condiciones las relaciones en este mundo diverso y pluricultural se establecen como relaciones de poder?, ¿bajo qué criterios de relación se establecen las jerarquías que anulan las relaciones igualitarias?, ¿desde dónde se puede abordar el 
problema social contemporáneo que significa unas relaciones culturales jerarquizadas, de exclusiones y de dominación?

La literatura especializada ofrece varias respuestas a este tipo de preguntas relativas a ese problema: el multiculturalismo, la interculturalidad y una poco atendida: el diálogo ch'ixi.

\section{El multiculturalismo: relaciones} jerarquizadas de tolerancia y autoafirmación de la propia

\section{identidad}

Multiculturalismo y multiculturalidad $^{2}$ aparecen como conceptos en los Estados Unidos, cuando muchas culturas, por procesos especialmente de inmigración, pueblan y cohabitan en un territorio en el que los choques ya endémicos de razas y culturas, constituidas en líneas de fuerza que siempre se muestran los colmillos, han derramado mucha sangre durante siglos.

El multiculturalismo implica aproximarse a estas relaciones entendiendo siempre la existencia de las fronteras, en las cuales los intercambios ocurren bajo el desbordamiento de la diferencia y sus discursos; conjugar otredades y alteridades, heterogeneidades y discontinuidades, diversidades y consumos.

Con el multiculturalismo se reconoce la coexistencia de "culturas" -grupos étnicos, raciales o religiosos, de una muy diversa

2 El antropólogo Eduardo Restrepo (2008) precisa: "En términos generales, para comenzar, se puede plantear que multiculturalidad hace referencia a un hecho histórico y social, mientras que multiculturalismo se refiere a uno jurídico y político. Entiendo multiculturalidad como la confluencia en un lugar y tiempo determinados de conglomerados sociales con expresiones culturales diversas" (p. 37). procedencia mundial- que ocupan en igual momento un mismo territorio; grupos culturales que demandan su autoafirmación; la proliferación de identidades globales que reclaman un estatus de reconocimiento.

El multiculturalismo, por su ubicación en las lógicas de la posmodernidad (Jameson, 1998), construye sujetos y subjetividades que se redefinen por la irrupción de una pluralidad de campos de acción para la negociación de conflictos y para la autoafirmación, que entrelaza la cultura con la afirmación y el fomento de la diferencia. Los emergentes campos de autoafirmación cultural saturan el espacio y se expanden; un mundo que se plantea como descentrado, cuyo efecto se plasma en la proliferación de identidades globales que demandan estatus y reconocimiento; en la disolución de las fronteras nacionales y del sentido de pertenencia y de geoespacialidad; en los escenarios en los que se asume la integración y en la multiplicación de instancias de afirmación. Entonces, en la lógica de la globalización, se trasiega de la igualdad a la diversidad. Los asuntos culturales son ahora el centro de reflexión. Las demandas tradicionales de bienestar social coexisten con exigencias de carácter simbólico. Y en este horizonte se origina una nueva utopía: la autoafirmación y la libre autodeterminación de los sujetos y de los grupos étnicos.

Los nuevos tiempos y los nuevos escenarios obligan a que igualdad, otredad y diferencia sean pensadas e inscritas en otros espacios, determinados por el impacto de la globalización. En la utopía multicultural, las formas culturales son consideradas integrales y múltiples, incluyentes y promotoras de otredades, que son posibles en una infinitud de espacios, en las migraciones y 
en los discursos de la tolerancia, todos estos cobijados en las prácticas de consumo. En estas, las diferencias culturales significan confrontación y yuxtaposición de tiempos y espacios, en los que se establecen jerarquías que se intentan armonizar.

Hay allí una reconceptualización de las identidades culturales que se sustenta en un sistema de valores propuestos en arreglo a diferentes estilos de vida, distintas percepciones, diversas maneras de representarse que terminan estableciéndose como superiores. Siguiendo a Žižek (1998),

la universalidad "real" de la globalización actual (a través del mercado global) supone su propia ficción hegemónica (o incluso ideal) de tolerancia multiculturalista, respeto y protección de los derechos humanos, democracia y otros valores por el estilo; supone también la propia "universalidad concreta" seudohegeliana de un orden mundial cuyos rasgos universales -el mercado mundial, los derechos humanos y la democracia- permiten que florezcan diversos "estilos de vida" en su particularidad (p. 17).

El multiculturalismo es un fenómeno contemporáneo, resultante de la concurrencia de diferentes grupos culturales, en los cuales pueden reconocerse caracteres y fronteras definidos con precisión, contradictorios entre sí, pero cuyas deficiencias se resuelven gracias a la tolerancia. Esta tolerancia, para quienes la observan con resistencia, se instaura como ficción, con un fuerte carácter estatal, con el propósito de imponer el reconocimiento de la diferencia cultural que contribuye a la continuidad y el reforzamiento de la globalización. Este encuentro, si bien propugna la inhibición de prácticas discriminatorias y de marginalidad, recibe como fuerte crítica el hecho de que frecuentemente no logra trascender una tolerancia pasiva. De esta manera, el multiculturalismo es hallado como poco o no resueltamente conducente a la constitución de unas relaciones de igualdad que estén presentes no solo en la norma, sino también en el ejercicio del poder en los diferentes grupos que convergen. Tales prácticas multiculturales devienen en conflicto: marginaciones, exclusiones, discriminaciones, asimilación y jerarquizaciones.

Quienes han vivido la colonización desde abajo, desde la cultura dominada, se ubican en una perspectiva muy diferente a la de las pretensiones conciliadoras de la oficialidad internacional globalizadora. Es la mirada que reconoce, en primer lugar, la vinculación de la política al poder y a la jerarquización en horizontes de larga duración, que tienen su origen en la Colonia (Rivera Cusicanqui, 1993).
El multiculturalismo oficial [...] ha sido el mecanismo encubridor por ex- celencia de las nuevas formas de colo- nización. Las élites adoptan una estra- tegia de travestismo y articulan nuevos esquemas de cooptación y neutraliza- ción. Se reproduce así una "inclusión condicionada", una ciudadanía recor- tada y de segunda clase, que moldea imaginarios e identidades subalterni- zadas al papel de ornamentos o masas anónimas que teatralizan su propia identidad (Rivera Cusicanqui, 2010).

Žižek (1998) agregaría a esta perspectiva indiana que el multiculturalismo busca naturalizar el capitalismo, y por eso lo invisibiliza: "Se define a través de una distancia respecto a un Otro al que se le descarta y denuncia como ideológico" (p. 156); y añade: “El respeto multiculturalista por la 
especificidad del Otro es precisamente la forma de reafirmar la propia superioridad" (p. 172).

Los actores culturales débiles están, frecuentemente, relacionados con condiciones de raza/etnia, con sus consecuentes maneras de racismo. A este respecto dice Žižek (1998):

El racismo posmoderno contemporáneo es el síntoma del capitalismo tardío multiculturalista, y echa una luz sobre la contradicción propia del proyecto ideológico liberal-democrático. La "tolerancia" liberal excusa al otro folclórico, privado de su sustancia (como la multiplicidad de "comidas étnicas" en una megalópolis contemporánea), pero denuncia a cualquier otro "real" por su "fundamentalismo", dado que el núcleo de la otredad está en la regulación de su goce: el "otro real" es por definición "patriarcal", "violento", jamás es el otro de la sabiduría etérea y las costumbres encantadoras. Uno se ve tensado aquí a reactualizar la vieja noción marcuseana de "tolerancia represiva", considerándola ahora como la tolerancia del Otro en su forma aséptica, benigna, lo que forcluye la dimensión de lo "Real del goce del Otro" (p. 172).

Aquí, el racismo para Žižek alcanza su mayor sofisticación cuando reconoce la humanidad del otro.

\section{La interculturalidad: tensiones, diálogos y reconocimiento del otro desde las diferencias}

La interculturalidad, como probabilidad de interacción entre diversos, se sustenta en el reconocimiento de los otros en una integración de las diferencias (de cultura, de etnia, de clase social y de otras categorías), en un diálogo que se tensiona de manera permanente por sus elementos conflictivos. Supone el reconocimiento de las diversas culturas que se han relacionado históricamente bajo el signo de la colonización y que buscan alguna manera de hacer fecunda la diferencia:

Si la interculturalidad se funda en la
necesidad de construir relaciones entre
grupos, como también entre prácticas,
lógicas y conocimientos distintos, con
el afán de confrontar y transformar las
relaciones del poder (incluyendo las es-
tructuras e instituciones de la sociedad)
que han naturalizado las asimetrías so-
ciales, la multi o pluriculturalidad sim-
plemente parte de la pluralidad étnico-
cultural de la sociedad y del derecho a
la diferencia (Walsh, 2002).

Para Walsh (2005), la interculturalidad rediseña los proyectos de sociedad y de Estado, de-construyendo nociones de relaciones y de bienestar que han sido asumidas por las élites como sus formas naturales. También es la posibilidad concreta de alterar las relaciones de poder que se gestan en los sectores subalternizados coloniales y que, por tanto, suponen procesos de decolonialidad.

Ese concepto de interculturalidad cobra sentido en América Latina, y su corpus teórico está a cargo de los pensadores del Giro Decolonial, el movimiento indígena ecuatoriano, el movimiento aymara, el movimiento indígena colombiano, entre muchos otros.

La interculturalidad señala y significa procesos de construcción de un conocimiento otro, de una práctica política otra, de un poder social (y estatal) otro y de una sociedad otra; una forma otra de pensamiento relacionada con y contra la modernidad/colonialidad, y un paradigma otro que es pensado a través de la praxis política. En contraste con los constructos teóricos creados dentro de la academia para ser aplicados a ciertos objetos o "casos" para el análisis, la interculturalidad, tal como 
es presentada y comprendida aquí, es un concepto formulado y cargado de sentido principalmente por el movimiento indígena ecuatoriano, concepto al que este movimiento se refiere hacia 1990 como "un principio ideológico". Como tal, esta configuración conceptual es por sí misma "otra" (Walsh, 2007, p. 175).

Esta praxis se ha construido por las resistencias de las poblaciones marginales en razón de la etnia/raza y se ha constituido en un proyecto que integra lo político, lo social y lo epistémico. Ahora bien, las distintas concepciones de lo multicultural establecen marcas diferenciales entre uno y otro grupo, una y otra cultura, con márgenes, límites y fronteras estructuradas y definidas, en el que se hacen más claras las reivindicaciones y las acciones afirmativas de cada uno de los grupos que consolidan, validan y defienden las identidades, pero que, para el caso nuestro, se multiplican también a lo largo de gran parte del territorio nacional. Las márgenes que separan un grupo de otros son, con frecuencia, difusas. $\mathrm{Y}$ estos rasgos, estas fronteras nebulosas, deberían permitir procesos interculturales fuertes y mayoritariamente logrados; sin embargo, estos se ven obstruidos y ahogados por las reiteradas y complejas desigualdades que resultan de las relaciones de poder constantes. Las culturas domeñadas, avasalladas, se resuelven más fácilmente por la aculturación que por la interacción.

Lo intercultural nos refiere una interrelación entre diversos, en los que cada quien tiene un estatus de equilibrio y de paridad. Sin embargo, inquieta cuando se indaga por quiénes y bajo qué criterios se establecen estas condiciones de iguales. Como ejemplos que pueden suscitar esa inquietud, ¿quiénes incluyen y reconocen a otros en situación de equidad (cultural, de raza, de género...)?, ¿quiénes estipulan los lenguajes apropiados y valederos, para no ser radicales, no refiriéndonos a distintas lenguas sino, como caso, a registros o variantes de lengua? Si bien existen estatutos, normas y leyes que oficializan estas prácticas interculturales, no es menos cierto que estas formas de relacionamiento dependen más de los propósitos y las prácticas concretas de quienes las ejercen. Encuentro que aun allí dicha noción de interculturalidad abarca unas jerarquías, unos predominios y unas exclusiones (pues toda inclusión comprende, por esencia, la posibilidad de la marginación), esto es, una práctica relacional que se origina en los encuentros y en el contacto mismo entre un entramado social en el que convergen diversidades de todo tipo.

En este orden, lo intercultural como práctica y no solo como discurso no supone, inherentemente, la transgresión de unas formas hegemónicas que se enmarcan en nuestras matrices culturales. Así, se despiertan suspicacias frente a si en ella siguen superviviendo discriminaciones de diversos orígenes y jerarquías, que se traducen en violencias y marginalidades.

\section{EL DIÁlogo $\mathrm{CH}^{\prime} I X I$ Y EL PROYECTO MESTIZO}

En Colombia, el movimiento indígena empieza a principios de los años setenta con el surgimiento del Consejo Regional Indígena del Cauca (CRIC) ${ }^{3}$, mientras que en Bolivia ya desde finales del siglo XIX, los pueblos aymara habían constituido los llamados “Apoderados Generales" (Ticona, 2003), en la lucha contra la Ley de Exvinculación que

3 Véase la página del CRIC: http://www.cric-olombia.org/index. php?option=com_content\&view $=$ article\&id $=38 \&$ Itemid $=60$ 
prohibía reconocer jurídicamente a las autoridades tradicionales. La conformación de los Apoderados Generales tiene antecedentes en la larga lucha boliviana que en 1781 había producido la rebelión de Tupaq Katari, parte de las movilizaciones de los Andes como respuesta a los intentos de España por afianzar su poder en América. La lucha boliviana conduce al surgimiento de un pensamiento indianista que se desprende de la perspectiva marxista ortodoxa y se pone en busca de un pensamiento propio descolonizador con pensadores indígenas como Fausto Reinaga y Silvia Rivera Cusicanqui.

Silvia Rivera Cusicanqui propone la visión descolonizadora en relación con la perspectiva liberal, que tiene, para ella, viarias características: la primera es que se funda en una concepción lineal del tiempo, que comporta una perspectiva de desarrollo como progreso sin retorno y que supone que el futuro seguirá siendo colonizador, como hasta ahora ha sido. La segunda es una perspectiva etnocéntrica que deriva en la formulación del multiculturalismo benevolente que pretende preservar las culturas indígenas como algo folclórico, pero no establece un verdadero diálogo con su pensamiento ni con sus posiciones políticas.

Se trata, por supuesto, de un problema de saber-poder en el cual la academia ha contribuido a despolitizar la mirada sobre las comunidades indígenas, lo que se deriva de la perspectiva colonizadora del norte. En Rivera Cusicanqui hay una insistencia sobre la lengua con la cual se nombra el mundo. Las denominaciones académicas sobre los pueblos indígenas reproducen la mirada colonizadora, como ocurrió con la primera antropología, según lo refiere Geertz (2001), para quien el pecado original de la etnografía consistió justamente en servir de instrumento de colonización. No obstante, el discurso de la diversidad cultural no apunta a una perspectiva descolonizadora, justamente por su vaciamiento de una postura política y la adopción de un lenguaje aséptico que no persigue consecuencias en la práctica social.

En este tono, Rivera Cusicanqui critica a Mignolo, que habla de una "geopolítica del conocimiento", y ella, en tono polémico, prefiere hablar de una "economía política del conocimiento", para no limarle las garras al pensamiento decolonial. En todo caso, Mignolo (2007) reconoce en ella un aporte por su perspectiva epistemológica relacionada con su análisis sobre la historia oral:

Las alternativas a la modernidad, esto
es, la descolonización del saber, tiene
que provenir también de formas de
pensar que fueron desprestigiadas por
la modernidad del saber. La colonia-
lidad del saber son, por lo tanto, for-
mas de conocimientos que fueron en
su momento desprestigiadas y que, en
este momento, se afirman como posi-
ción crítica a la idea de "totalidad" que
define la modernidad del saber (e. g.,
cristianismo, liberalismo, marxismo,
ciencia, filosofía). La colonialidad del
saber revela el exceso, aquello que es-
capa a la totalidad (p. 203).

\section{LA HISTORIA ORAL}

La historia oral, no como tradición metodológica de las ciencias sociales, sino como práctica cultural que produce la memoria colectiva, constituye la forma predominante de autointerpretación de las culturas. Las personas y las culturas se ofrecen como relato, existen colectivamente como relato principalmente oral, porque este es la forma en la que se materializa la memoria (Augé, 
1998). La posibilidad de diálogo intercultural que abre la hermenéutica (Ángel, 2010), especialmente con Gadamer (1977), permite comprender que el conocimiento de otra cultura solo es posible mediante el reconocimiento de su autoridad, y solo puede darse en los términos de cada cultura. Esta idea, que en el fondo es una crítica al colonialismo y al etnocentrismo europeos, se hace fuerte en las culturas que asumen su propia historia en forma crítica y persistente. Las culturas orales crean rituales mediante los cuales se vinculan al tiempo colectivo.

El abordaje que hace Rivera Cusicanqui de la memoria colectiva se basa en Halbwachs, discípulo de Durkheim, que concibe la memoria como resultante de una articulación social. Frente al problema de la historia oral como fuente metodológica no canónica, la crítica de Rivera Cusicanqui consiste en que el problema no radica en la veracidad o no de las fuentes, sino en la forma instrumental de abordar el estudio de la historia, de modo que la metodología se convierte en el criterio de verdad, con lo cual se descalifican otras formas de saber. Mignolo (2007) reconoce:

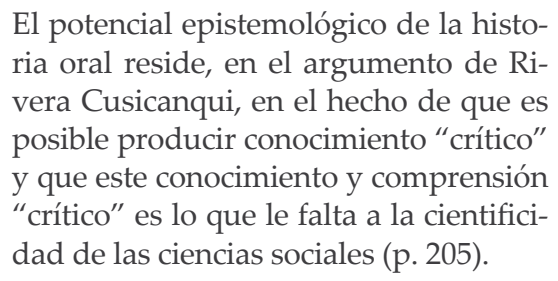

Esta afirmación, según el autor, es producida por Rivera Cusicanqui mediante su trabajo en el Taller de Historia Oral Andina (THOA), que tiene un origen en la lucha contra el colonialismo y que se concibe dentro de una acción política. De esta manera, la historia oral no es propiamente un problema metodológico, sino de acción frente a lo que Rivera Cusicanqui (1990) llama "el colonialismo interno":

La historia oral en este contexto es, por eso, mucho más que una metodología "participativa" o de "acción"; es un ejercicio colectivo de desalienación, tanto para el investigador como para su interlocutor. Si en este proceso se conjugan esfuerzos de interacción consciente entre distintos sectores, y si la base del ejercicio es el mutuo reconocimiento y la honestidad en cuanto al lugar que se ocupa en la "cadena colonial", los resultados serán tanto más ricos [...] Por ello, al recuperar el estatuto cognoscitivo de la experiencia humana, el proceso de sistematización asume la forma de una síntesis dialéctica entre dos (o más) polos activos de reflexión y conceptualización, ya no entre un "ego cognoscente" y un "otro pasivo", sino entre dos sujetos que reflexionan juntos sobre su experiencia y sobre la visión que cada uno tiene del otro (citada en Mignolo, 2007, p. 206).

En esta forma, anota Mignolo que la historia oral, como la concibe Rivera Cusicanqui, le aporta el elemento que le falta a la investigación acción participativa (IAP) postulada por Fals Borda, que consiste en "la experiencia histórica de los sujetos relacionados por estructuras de poder y, en este caso, principalmente por la colonialidad del poder" (Mignolo, 2007, p. 206). Si bien estas afirmaciones sobre la IAP son, al menos, discutibles, como se puede observar en Ángel (2010), sí revelan el talante de la historia oral como es propuesta por Rivera Cusicanqui.

Ahora bien, la práctica de la memoria que transcurre en las cocinas y en otros espacios rituales produce lo que la autora llama el ajayu, que es ese rasgo que hace pensar que alguien pertenece a algún lugar, esa alma colectiva, que permite transcurrir en el mundo sin perderse. Refiera a los neoyorkinos que 
se hallan perdidos en un mundo que creen de ciudadanos iguales, pero que en realidad se funda en bases profundas de explotación y de colonialismo, dado que el ajayu se ve, se nota en la gente:

Me di cuenta un día, mientras iba por el tren subterráneo de Nueva York, que nadie de los pasajeros tenía ajayu, salvo una negra corpulenta que musitaba un blues, en cuyos "ojos antiguos" destellaba la chispa de la memoria, del arraigo colectivo. Para nosotras, la wawa que ha perdido el ajayu se enferma, se constipa, tiene pesadillas sudorosas y comienza a perder peso (Rivera Cusicanqui, 2010, p. 3).

En esta forma se abre una discusión profunda frente a la perspectiva de la mundialización de la cultura (Ortiz, 1997), que parece estandarizar tanto las formas como la ética y el conocimiento. No obstante, la perspectiva decolonial piensa el problema en términos que rebasan los cánones de lo que se ha llamado "premodernidad" o "posmodernidad":

Para mí que la teoría del ajayu podría solventar este enigma, por su forma práctica de articular al individuo con la colectividad, a la memoria con el presente, a través de ritos como el de Todos Santos, en los que reconciliamos la modernidad del hecho mercantil con el tejido cultural de la memoria, abriendo el corazón a penas y llantos, a sentimientos de orfandad y pertenencia, mientras bautizamos las t'ant'awawas con los nombres de nuestros muertos queridos. Al hacerlo, la familia se conecta con un denso flujo de pasado, y las nuevas generaciones comienzan a nutrirse de sucesos y relatos familiares, que quizás serán claves para su salud espiritual en el futuro. Para mí, estos rituales son también una forma de protegerme contra los coletazos de la ciencia

4 La wawa es la niña pequeña o el niño pequeño. liviana, aquella que proclama que la única forma de ser nosotros mismos es reciclando la chatarra, ideológica y tecnológica, que produce Occidente (Rivera Cusicanqui, 2010, p. 4).

La memoria colectiva, la raíz del ajayu, del alma que identifica, del sentido colectivo, es la forma en que una cultura se comprende a sí misma y tramita el tiempo. Por eso, el tiempo es justamente el problema para la mirada del norte.

\section{El tiempo decolonial}

Para Rivera Cusicanqui (2010), que vive en un tiempo muy diferente al del norte, inaugurado por Pablo de Tarso, que concibió la historia en función de una teleología escatológica, "lo que se ha vivido en los años recientes evoca una inversión del tiempo histórico, la insurgencia de un pasado y un futuro, que puede culminar en catástrofe o en renovación" (p. 10). La autora está hablando de los levantamientos y bloqueos de caminos que ocurrieron de 2000 a 2005 y que tuvieron el mismo escenario que las rebeliones de 1781 en la ciudad de El Alto. Lo que fue mirado como una rebelión sin sentido en el pasado, es oteado hoy como la reivindicación del espíritu aymara, que logra poner sus voces en la política nacional y se convierte en una "victoria de los sublevados", de modo que se produce un cambio desde el interior del tiempo en la manera de concebir la política, lo que toca los principios de identidad. En esta forma encuentra que hay un tiempo indígena que no es el mismo que el tiempo paulino. Es un tiempo en el que

no hay "post" ni "pre" [se refiere a los calificativos de posmodernidad y de premodernidad] en una visión de la historia que no es lineal ni teleológica, 
que se mueve en ciclos y espirales, que marca un rumbo sin dejar de retornar al mismo punto. El mundo indígena no concibe a la historia linealmente, y el pasado-futuro están contenidos en el presente: la regresión o la progresión, la repetición o la superación del pasado están en juego en cada coyuntura y dependen de nuestros actos más que de nuestras palabras (Rivera Cusicanqui, 2010, p. 54).

Esta perspectiva del tiempo indígena impregna la vida cotidiana tanto como los grandes acontecimientos. Es fundamento de una cosmovisión que se traduce en las siembras, en la concepción de la naturaleza como Patcha mama y en una historia que se reinventa y que renace, que tiene su fuente en las raíces del presente que se sepultan tanto en el pasado como en el futuro.

Cuando Geertz asume una postura epistemológica del investigador en términos de intérprete, reconoce que las culturas tienen el poder de autointerpretarse; por consiguiente, hay un reconocimiento de la autoridad de esa cultura que no puede comprenderse sino en sus propios términos, $\mathrm{y}$ estos términos no son los mismos que los del investigador, cuyo pensamiento categorial, occidental, transcurre de un modo muy diferente al de los nativos de la cultura con la que se dialoga. Y lo más radical que suele ocurrir se refiere a la concepción del tiempo. En el discurso del antropólogo no se considera, tampoco, la implicación política que tienen las diferentes concepciones del tiempo, porque se trata de un discurso etnográfico contemplativo, que plantea un diálogo entre culturas con un propósito que se ubica exclusivamente en el saber y no en la práctica política.
Esta concepción ("concepción" porque se encuentra dentro, en el vientre, porque preña toda la vida) del tiempo pone en juego una dinámica de acción que invierte la perspectiva colonizadora y la rompe en su base:

La experiencia de la contemporaneidad nos compromete en el presente -aka pacha- y a su vez contiene en sí misma semillas de futuro que brotan desde el fondo del pasado: qhip nayr uñtasis sarnaqapxañani. El presente es escenario de pulsiones modernizadoras y a la vez arcaizantes, de estrategias preservadoras del statu quo y de otras que significan la revuelta y renovación del mundo: el pachakuti. El mundo, al revés del colonialismo, volverá sobre sus pies realizándose como historia solo si se puede derrotar a aquellos que se empeñan en conservar el pasado, con todo su lastre de privilegios mal habidos. Pero si ellos triunfan, "ni el pasado podrá librarse de la furia del enemigo", como diría Walter Benjamin ${ }^{5}$ (Rivera Cusicanqui, 2010, p. 55).

De alguna manera, los antropólogos habían advertido en sus investigaciones el abismo que se abría ante las culturas de América frente a la concepción del tiempo. En Tristes trópicos, Levy Straus (1988) señala:

Es imposible no sentir nostalgia ante la tribu de los bororos, una sociedad que abolía el tiempo. ¿Qué deseo más profundo que el de querer vivir en una suerte de presente que es un pasado revivificado sin cesar y mantenido tal como era a través en los mitos y las creencias?

Para él, el tiempo de los bororos es solo revivificación del pasado en el tiempo mítico. Pero para las culturas indígenas es renacer incesante y nuevo. Es mucho más que como lo concibe Mead (1971), que mencionaba

5 Se refiere al libro de Benjamin (1969): Illuminations. 
culturas de Oceanía para las cuales el futuro se encontraba en el pasado:

A juicio de los occidentales, el futuro está delante de nosotros. A juicio de muchos pueblos de Oceanía, el futuro reside atrás, no adelante. Para construir una cultura en la que el pasado sea útil y no coactivo, debemos ubicar el futuro entre nosotros, como algo que está aquí listo para que lo ayudemos y protejamos antes de que nazca, porque de lo contrario será demasiado tarde (p. 106).

Más bien, el futuro, como lo indica Rivera Cusicanqui, es una pulsión del presente cuyo resultado no está marcado de antemano como destino (destino de dominación y prevalencia de una clase), sino como permanente reinterpretación del tiempo que permite el proyecto de emancipación.

En la perspectiva etnológica, Augé (1998) se aproxima a esta posición en términos de memoria como relato que otorga la identidad y que hace posible el trámite del tiempo; es decir, el relato-memoria es lo que permite el proyecto. $Y$ el relato es presente, la memoria es presente, es interpretación constante que se modifica de manera permanente como comprensión del tiempo. El tiempo es memoria, existe como memoria que se construye en el presente. La memoria no es algo substancial que tiene una existencia en las sociedades y que es preciso "recuperar". El relato-memoria se produce como práctica histórica de reinterpretación en el presente del tiempo que renace.

Es por esta ubicación en un tiempo cósmico circular por lo cual Rivera Cusicanqui entiende al indígena como ser de la Modernidad. En esta forma, adopta la postura de García Canclini (1989), que plantea la posibilidad de entrar y salir de la Modernidad, lo cual solo es posible en una perspectiva del tiempo circular, en el cual los antecedentes existen tanto en el pasado como en el futuro, como pulsión simultáneamente arcaizante y modernizante. En esta forma, la concepción indígena del tiempo dota a estos pueblos de una cualidad emancipadora.

\section{La lengua con la que se nombra el mundo}

En la aproximación de dos culturas distantes ocurre que cada una de ellas hable en una lengua diferente a la otra. $Y$ en las reflexiones de la etnografía, este problema se ha planteado con insistencia. De hecho, Malinovsky recomendaba, para perderse dentro de la cultura "estudiada", dominar la lengua nativa, cosa que los antropólogos han hecho de manera sistemática. El problema radica en que tanto el análisis como el informe final se suelen escribir en la lengua de los estudiosos que llegan a conocer a los extraños, y pocas veces los análisis y los informes son traducidos a la lengua de la cultura "estudiada". En este hecho se manifiesta de manera evidente la tradición colonial de la etnografía.

Ahora bien, cuando la cultura colonialista se siente con derecho a ocupar el territorio de la cultura colonizada, lo primero que impone es su lengua. El colonizado tiene que empezar a hablar en la cultura del recién llegado. Y como resultado, se van perdiendo las formas de relatar la propia historia, las propias creencias y los propios sueños, porque se va perdiendo la lengua propia. Este es el caso de muchos palenques de cimarrones, como el de San Basilio, donde se conservan reliquias de las lenguas centroafricanas de donde provenían los ancestros, pero ya se perdió 
la sintaxis (Ángel, 2007). Ya el mundo no se nombra allí en la lengua propia.

Y esto es así porque la relación de los hablantes siempre se da en relación con el contexto; sin embargo, como lo señaló Bajtín (1989), el contexto no es un plus: el contexto hace parte de la semántica del enunciado, de modo que los saberes que se comparten en una cultura se construyen de acuerdo con los roles y las maneras de construcción de los enunciados, porque no es posible construirse por fuera del lenguaje-contexto; pero el contexto no es preexistente de manera discreta, sino que existe en el enunciado. El enunciado se construye en la fusión entre una forma material (no es exclusividad del lenguaje verbal la expresión, sino que intervienen el lenguaje verbal y el icónico) del lenguaje y el contexto. En esto, Bajtín mantiene una cercanía con Vigotsky, puesto que para él no hay construcción social posible fuera del lenguaje, y no hay lenguaje posible fuera de la práctica de los hablantes en relación con el contexto.

Como es obvio, la práctica de la colonización constituye contexto, de la misma manera como este se construye con referencia a esta práctica y a la lengua en que se habla en las relaciones coloniales. Entonces, ya no hay historia propia, porque las narraciones que empiezan a imponerse son las del colonialista, los mitos que se relatan son los suyos, los ritos que se emplazan en la cultura son los que llegan a invadir la cultura nativa. No obstante, según el mismo Bajtín, esto no es absoluto ni ocurre de una manera indiscriminada. En su perspectiva de la cultura popular, se encuentra un profundo sentido emancipatorio, al señalar que esta cultura mantiene espacios de ritualidad y discursos subterráneos que permiten conservar el alma propia (Bajtín, 1974). Es en este sentido que Rivera Cusicanqui hace un análisis sobre la iconografía aymara respecto a la manera como un cronista qhichwa, Waman Puma, relata dos hechos históricos diferentes y distantes en el tiempo. El uno es la muerte de Atawallpa en 1532, y el otro es la ejecución de Tupaq Amaru I, en 1571. La representación de la muerte de Atawallpa es dibujada por Puma en forma de decapitación con un cuchillo por unos españoles. Esta misma imagen la dibuja en el caso de Tupaq Amaru I:

Solo este último murió decapitado, mientras que al Inka Atawallpa le aplicaron la pena del garrote. La "equivocación" de Waman Puma revela una interpretación y una teorización propia sobre estos hechos: la muerte del inka fue, efectivamente, un descabezamiento de la sociedad colonizada. Sin duda hay aquí una noción de "cabeza" que no implica la usual jerarquía respecto al resto del cuerpo: la cabeza es el complemento del chuyma -las entrañas- y no su dirección pensante [...] Su decapitación significa entonces una profunda desorganización y desequilibrio en el cuerpo político de la sociedad indígena. Pero esta visión sombría y premonitoria, que se expresó en el ciclo de 1781 , puede contrastarse con la imagen del indio poeta y astrólogo, aquel que sabe cultivar la comida, descifrar las marcas del tiempo-espacio y trajinar por el mundo, más allá de las contingencias de la historia (Rivera Cusicanqui, 2010). 
Figura 1. Relatos de la ejecución de Atawallpa y Tupaq Amaru por Waman Puma

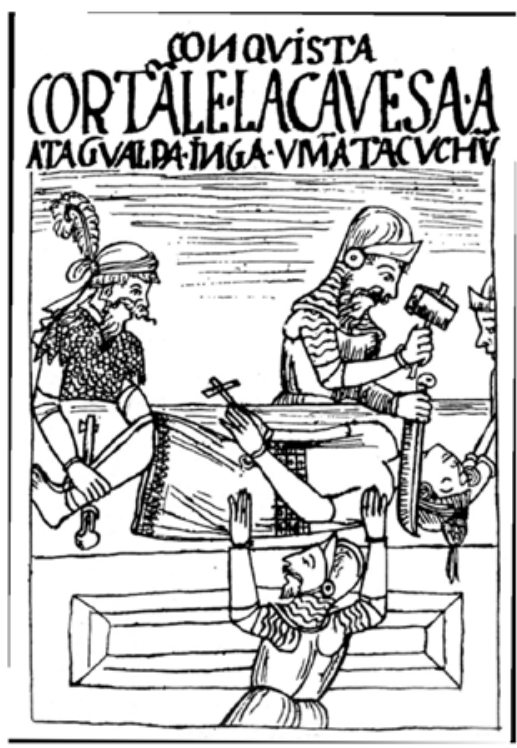

Conquista. Cortanle la cavesa a Atagualpa Inga Uman Tauchun / Murió Atahualpa en la ciudad de Caxamarca.

El aparente error de Waman Puma respecto a la forma como "en realidad" ocurrieron las dos muertes -que por supuesto no se trata de un error por falta de fuentes ni por desconocimiento de los acontecimientosconduce a Rivera Cusicanqui, en un escrito posterior (2010a), a su teoría de la narración, que más que verbal, en este caso, es visual y constituye "una interpretación y no una descripción de los hechos. La sociedad indígena fue descabezada". En las descripciones icónicas de Puma, Rivera Cusicanqui (2010) encuentra su teorización visual del sistema colonial:

Más que en el texto, es en los dibujos donde el cronista despliega ideas propias sobre la sociedad indígena prehispánica, sobre sus valores y conceptos del tiempo-espacio, y sobre los significados de esa hecatombe que fue la colonización y subordinación masiva de

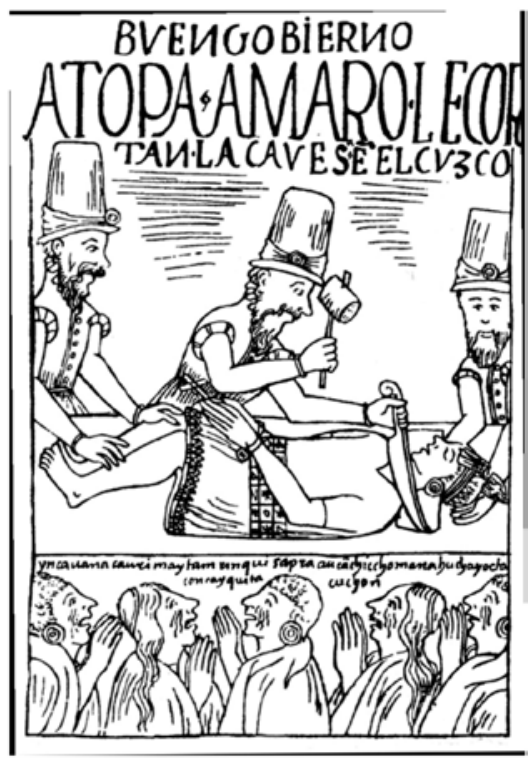

Buen gobierno. A Topa Amaro le cortan la cavesa en el cuzco.

la población y el territorio de los Andes a la corona española.

Las imágenes de Waman Puma, que son icónico-verbales, constituyen un relatoteoría, y allí se puede encontrar la manera como una cultura se interpreta a sí misma. En esta forma, probablemente al historiador le interesa saber cómo se desarrollaron en realidad los hechos; pero su versión no es mejor que la de la cultura que los interpreta. El historiógrafo va tras el hecho aislado, no tras la forma como la cultura se interpreta. $\mathrm{Y}$ aquí se revela claramente la perspectiva colonialista de las formas como se nombra el mundo. De manera programática, Rivera Cusicanqui (2010) encuentra que la forma para empezar a romper con la sociedad colonial, que se manifiesta en el colonialismo interno, depende de lo siguiente: 
La descolonización de nuestros gestos, de nuestros actos y de la lengua con que nombramos el mundo. El retomar el bilingüismo como una práctica descolonizadora permitirá crear un "nosotros" de interlocutores/as y productores/as de conocimiento, que puede posteriormente dialogar, de igual a igual, con otros focos de pensamiento y corrientes en la academia de nuestra región y del mundo (Rivera Cusicanqui, 2010).

La idea del bilingüismo es una clave de la forma como puede plantearse la superación del etnocentrismo de la sociedad colonial.

\section{El etnocentrismo}

La antropología fue tomando forma de disciplina de la diversidad cultural en la medida en que descubrió sus raíces colonialistas y la destrucción masiva de enormes culturas que fueron arrasadas por los europeos. Y el pensamiento antropológico sobre su propio saber comprendió que la práctica investigativa del etnógrafo no podía ser otra cosa que un diálogo entre culturas y que no podía centrarse en la cultura que siempre había dominado (Geertz, 2001). Por supuesto, no hay posibilidad de pensar mediante el vaciamiento absoluto de los supuestos propios sobre una cultura que es ajena a la de quien se aproxima desde fuera; por eso, Geertz plantea el estudio de las culturas como interpretación, solo que es una interpretación en los términos de la cultura estudiada, no en los de la cultura de quien estudia. Esta posición que se aproxima a la hermenéutica de Gadamer (Herrera, 2009) en todo caso mantiene los términos de las investigaciones en el tono limpio del diálogo y de la conciliación que ha combatido el etnocentrismo, y parece olvidar la verdadera liquidación de pueblos enteros por las culturas de quienes ahora trabajan con manos limpias. No obstante, hay aquí una reflexión que debe considerarse detenidamente. Augé (1998) la formula de la siguiente manera:

Las sociedades remotas ofrecen al observador infinidad de palabras nuevas. Pero durante tiempo ha estado, y sigue estando actualmente, paralizada por un mal insidioso: el etnocentrismo $y$, peor aún, el temor al etnocentrismo. El temor al etnocentrismo es respetable y merece el mismo respeto que manifiesta hacia los demás cuando postula que no hay que reducir los pensamientos, ni siquiera los más salvajes, a la esclavitud, ni asimilarlos por desprecio a su originalidad. Pero, a veces, es mal consejero, pues nada nos dice de la existencia de pensamientos que, nacidos en nuestras latitudes, han encontrado asilo en palabras exóticas, ni de otros venidos de lejos que han sido disimulados en palabras que nos son familiares (sobre las grandes migraciones de pensamientos, pese a ciertas hipótesis generales, estamos lejos de saberlo todo) (pp. 12-13).

Augé, como un buen antropólogo, reconoce la dignidad del temor al etnocentrismo, pero se pregunta por su propio pensamiento que puede ser conmovido por los pensamientos que encuentra en una cultura a la cual se ha aproximado como europeo. $\mathrm{Y}$ encuentra que el miedo al etnocentrismo y, por consiguiente, el afán de mantener la independencia incólume de la cultura otra no le permite establecer un verdadero diálogo con ella:

Un autor como Georges Devereux ha demostrado claramente, tomando como ejemplo a los indios mohaves, de qué manera un modelo de pensamiento tan diferente del nuestro es capaz de tensionar nuestras propias categorías, 
ofreciéndoles así una oportunidad de definirse de nuevo (Augé, 1998, p. 17).

El problema para Augé empieza a ser la lucha contra la pureza cultural de las culturas llamadas "remotas" y la lucha contra la pureza de la cultura del racionalismo europeo, que no es capaz de conmoverse con la tensión del pensamiento de aquellas culturas, porque se empecina en la racionalidad supuestamente científica, cuando en muchas ocasiones ni siquiera puede considerarse como tal. De lo que se trata, para Augé (1998), es justamente de encontrar una vía posible y real al mestizaje cultural, que pueda enriquecer a cada cultura que se tensa con la otra en un diálogo fecundo.

La posición de Devereux resulta pues paradójica en apariencia, pero solo en apariencia. Si utiliza la cultura de otros, lo hace para disipar la miopía o la ceguera que pueden suscitar las rutinas y automatismos de nuestra cultura. Pero este razonamiento se podría aplicar del mismo modo a los indios mohaves. Encerrarse en una cultura única es lo que produce ceguera. El conocimiento de otra cultura tiene el mérito de relativizar toda adhesión a una sola cultura. Esta relativización no tiene nada que ver, sino todo lo contrario, con poner en tela de juicio el racionalismo y la ciencia, incluso si sigue siendo verdad que lo que consideramos ciencia no siempre lo es. La relativización de una cultura por otra (el cambio de "marco de referencia") es, en el fondo, un ejercicio anticulturalista que respeta ante todo, en cada cultura, el poder que posee para desestabilizar a las restantes (p. 18).

Rivera Cusicanqui encuentra la misma inquietud, pero lo hace en una perspectiva política como un asunto programático. Se trata de su reconocimiento de la existencia del mundo $c h$ 'ixi, en su ponencia " $C$ 'hixinakax utxiwa" ("Existe también el mundo ch'ixi"), en la que empieza reconociendo que no se considera q'ara (culturalmente desnuda, usurpadora de lo ajeno), pues ha reconocido su doble procedencia, aymara y europea, y vive de su trabajo. $Y$ ese doble origen la lleva a reconocerse $c h^{\prime} i x i$, que es la forma como piensa que se mezcla en los mestizos sus orígenes dobles:

La noción ch'ixi, como muchas otras (allqa, ayni), obedece a la idea aymara de algo que es y no es a la vez, es decir, a la lógica del tercero incluido. Un color gris ch'ixi es blanco y no es blanco a la vez, es blanco y también es negro, su contrario. La piedra ch'ixi, por ello, esconde en su seno animales míticos como la serpiente, el lagarto, las arañas o el sapo, animales $c h^{\prime} i x i$ que pertenecen a tiempos inmemoriales, a jaya mara, aymara. Tiempos de la indiferenciación, cuando los animales hablaban con los humanos. La potencia de lo indiferenciado es que conjuga los opuestos [...] Así como el allqamari conjuga el blanco y el negro en simétrica perfección, lo ch'ixi conjuga el mundo indio con su opuesto, sin mezclarse nunca con él. Pero su heterónimo, chhixi, alude a su vez a la idea de mescolanza, de pérdida de sustancia y energía [...] Se dice chhixi de la leña que se quema muy rápido, de aquello que es blandengue y entremezclado. Corresponde entonces a esa noción de moda de la hibridación cultural "light", conformista con la dominación cultural contemporánea (Rivera Cusicanqui, 2010, pp. 79-80).

La noción de mestizaje intercultural en esta concepción permite comprender que la mezcla respeta los elementos que se unen. Para Rivera Cusicanqui, la noción expuesta por García Canclini en Culturas híbridas constituye una metáfora genética que tiene la implicación de fusión en una nueva especie que armoniza los contrarios en su interior; pero en la naturaleza los híbridos 
suelen ser estériles. La noción ch'ixi, al contrario, expresa la mezcolanza abigarrada de culturas que perviven en tensión de los elementos que luchan entre sí desde el tiempo de la memoria, que es conflictiva por aquello que reúne pero que no disuelve:

La metáfora del ch'ixi asume un ancestro doble y contencioso, negado por procesos de aculturación y "colonización del imaginario", pero también potencialmente armónico y libre, a través de la liberación de nuestra mitad india ancestral y el desarrollo de formas dialogales de construcción de conocimientos [...] La metáfora de la hibridez plantea que podemos "entrar y salir de la modernidad" como si se tratara de una cancha o de un teatro, no de una construcción -objetiva y subjetiva a la vez- de hábitos y gestos, de modos de interacción y de ideas sobre el mundo. La apuesta india por la modernidad se centra en una noción de ciudadanía que no busca la homogeneidad, sino la diferencia (Rivera Cusicanqui, 2010, p. 80).

Por supuesto, Rivera Cusicanqui piensa en el proyecto político que se desprende de esta reflexión sobre el mestizaje, y no se queda en la producción de un saber que sería tan estéril como el mulo híbrido que no engendra hijos:

Pero a la vez, al tratarse de un proyecto con vocación hegemónica, capaz de traducirse en términos prácticos en las esferas de la política y el Estado, supone una capacidad de organizar la sociedad a nuestra imagen y semejanza, de armar un tejido intercultural duradero y un conjunto de normas de convivencia legítimas y estables. Esto implica construir una patria para todas y para todos (Rivera Cusicanqui, 2010, p. 80).

Augé y Rivera Cusicanqui, que se tensionan en este intento de reflexión sobre el etnocentrismo y el temor al etnocentrismo, se conjugan aquí en una mezcla ch'ixi que se mueve entre la posibilidad de diálogo intercultural y el proyecto político de una sociedad que haga posible la tensión de lo diferente que ha convergido bajo el signo de la colonización, no del diálogo:

En esa sociedad deseable, mestizos
e indios podrían convivir en igual-
dad de condiciones, mediante la
adopción, por parte de los primeros,
de modos de convivencia legítimos
asentados en la reciprocidad, la redis-
tribución y la autoridad como servi-
cio. Asimismo, los indios ampliarían
y adaptarían sus nociones cultural-
mente pautadas de la convivencia
democrática y el buen gobierno, para
admitir formas nuevas de comunidad
e identidades mezcladas o ch'ixi, con
las cuales dialogarían creativamente
en un proceso de intercambio de sa-
beres, de estéticas y de éticas.

En este proyecto perviven los ancestros que retornan en un tiempo circular, que han sido decapitados en el pasado, como lo dibuja Waman Puma, y que desorganizó la sociedad de los indios como si fuesen un panal al cual le han matado la reina. Pero en el tiempo circular y en la mezcla $c h^{\prime} i x i$, el tiempo retorna nuevo y es posible la vida. La fusión verdadera es entre pensamiento y acción, entre saber y proyecto:

El pensamiento descolonizador que nos permitirá construir esta Bolivia renovada, genuinamente multicultural y descolonizada, parte de la afirmación de ese nosotros bilingüe, abigarrado y ch'ixi, que se proyecta como cultura, teoría, epistemología, política de Estado y también como definición nueva del bienestar y el "desarrollo". El desafío de esta nueva autonomía reside en construir lazos sur-sur que nos permitan romper los triángulos sin base de la política 
y la academia del norte. Construir nuestra propia ciencia -en un diálogo entre nosotros mismos- dialogar con las ciencias de los países vecinos, afirmar nuestros lazos con las corrientes teóricas de Asia y África, y enfrentar los proyectos hegemónicos del norte con la renovada fuerza de nuestras convicciones ancestrales (Rivera Cusicanqui, 2010, p. 73).

Las preguntas que se abren en esta reflexión respecto a otros contextos, como el nuestro, son múltiples y probablemente más dolorosas que las que se abren en una sociedad donde han pervivido los elementos que se juntan de manera $c h^{\prime} i x i$. Las preguntas aquí se refieren al alma colonizada, que ha sido sometida y despojada de dignidad y de memoria, y que aún produce la segregación de los pobres y de los campesinos que buscan en el blanqueamiento la posibilidad de integrarse a una sociedad que ha perdido sus raíces.

\section{REFERENCIAS}

Ángel, D. (2007). Narrativas y memoria. Revista Ánfora, 23(14), 165-184. Manizales: Universidad Autónoma de Manizales.

Ángel, D. (2010). Hermenéutica y metodologías de las ciencias sociales. Revista de Estudios de Filosofía (en prensa). Medellín: Universidad de Antioquia.

Augé, M. (1998). Las formas del olvido. Barcelona: Gedisa.

Bajtín, M. (1974). La cultura popular en la Edad Media y el Renacimiento. El contexto de François Rabelais. Barcelona: Barral.

Bajtín, M. (1989). El problema de los géneros discursivos. México: Siglo XXI.
Choc, M. (1997). La rueda. Recuperado de http://www.literaturaguatemalteca. org/mayacu2.htm

Gadamer, H. G. (1977). Verdad y método. Salamanca: Sígueme.

García Canclini, N. (1989). Culturas híbridas. Estrategias para entrar y salir de la modernidad. México: Siglo XXI.

Geertz, C. (1997). La interpretación de las culturas. Barcelona: Gedisa.

Geertz, C. (2001). Pensamiento local: ensayos para una interpretación de las culturas. Barcelona: Paidós.

Herrera, J. D. (2009). La comprensión de lo social. Horizonte hermenéutico de las ciencias sociales. Bogotá: Cinde.

Jameson, F. (1998). Teoría de la postmodernidad. Madrid: Trotta.

Levi-Strauss, C. (1988). Tristes trópicos. Barcelona: Paidós.

Mead, M. (1971). Cultura y compromiso. Buenos Aires: Granica.

Mignolo, W. (2007). El potencial epistemológico de la historia oral: algunas contribuciones de Silvia Rivera Cusicanqui. En Castro-Gómez, S. y Grosfoguel, R. (Comps.). El giro decolonial: reflexiones para una diversidad epistémica más allá del capitalismo global. Bogotá: Siglo del Hombre Editores - Universidad Central - Instituto de Estudios Sociales Contemporáneos - Pontificia Universidad Javeriana.

Ortiz, R. (1997). Mundialización y cultura. Buenos Aires: Alianza.

Restrepo Uribe, E. (2008). Multiculturalismo, gubernamentalidad, resistencia. En El giro hermenéutico de las ciencias sociales y humanas. Diálogo con la Sociología (pp. 35-48). Medellín: Universidad Nacional de Colombia. 
Rivera Cusicanqui, S. (1993). La raíz: colonizadores y colonizados. En Albó, X. y Barrios, R. (Coords.). Violencias encubiertas en Bolivia. La Paz: Cipca-Aruwiyiri.

Rivera Cusicanqui, S. (1999). La pérdida del alma colectiva. Recuperado de http://gonzaloportocarrero.blogsome. com/2009/09/21/la-perdida-del-alma -colectiva/

Rivera Cusicanqui, S. (2010a). Ch'ixinakax utxiwa: una reflexión sobre prácticas y discursos descolonizadores. Buenos Aires: Tinta Limón.

Rivera Cusicanqui, S. (2010b). Sociología de la imagen: una visión desde la historia colonial andina. En Ch'ixinakax utxiwa: una reflexión sobre prácticas y discursos descolonizadores. Buenos Aires: Tinta Limón.

Ticona, E. (2006). En el centenario de su nacimiento: Fausto Reinaga, el amauta descolonizador. Revista Mallki, 13(4). Recuperado de http://www.faustoreinaga. org/home/mallki/revistas/index.html

Unesco (2001). Declaración universal sobre la diversidad cultural. Recuperado de http://portal.unesco.org/es/ev.php url_ id=13179\&url_do=do_topic\&url_section $=201 . \mathrm{html}$
Walsh, C. (2002) Interculturalidad, reformas constitucionales y pluralismo jurídico. Boletín Instituto Científico de Culturas Indigenas (ICCI), 36(4). Recuperado de http://icci.nativeweb.org/boletin/36/ walsh.html

Walsh, C. (2005). (Re)pensamiento crítico y (de)colonialidad. En Walsh, C. (Ed.). Pensamiento crítico y matriz (de)colonial. Reflexiones latinoamericanas (pp. 13-35). Quito: Universidad Andina Simón Bolívar - Abya-Yala.

Walsh, C. (2007). Interculturalidad y colonialidad del poder. Un pensamiento $\mathrm{y}$ posicionamiento "otro" desde la diferencia colonial”. En Castro-Gómez, S. y Grosfoguel, R. (Comps.). El giro decolonial: reflexiones para una diversidad epistémica más allá del capitalismo global. Bogotá: Siglo del Hombre Editores Universidad Central - Instituto de Estudios Sociales Contemporáneos - Pontificia Universidad Javeriana.

Žižek, S. (1998). Multiculturalismo o la lógica cultural del capitalismo multinacional. Recuperado de http://caosmosis.acracia. net/wp-content/uploads/2008/07/zizek_ multiculturalismo.pdf 